\title{
26412 - AWAKE CARDIAC SURGERY USING A NOVEL TECHNIQUE: A PILOT FEASIBILITY STUDY
}

\section{Thomas Hemmerling MD, Ignatio Prieto, MD; Fadi Basile, MD; Nicolas Noiseux, University Of Montreal, Montreal, PQ, Canada}

INTRODUCTION. We recently presented a novel technique of regional anesthesia for off-pump aortocoronary bypass grafting (OPCAB) using high thoracic epidural analgesia (TEA) and femoral nerve block (FN) (1). In a pilot study, we investigated the feasibility of this technique in 10 patients undergoing elective OPCAB.

METHODS. Ten patients undergoing elective OPCAB with an ejection fraction of more than $30 \%$ were included after Ethics committee approval and written consent. In all patients, central venous pressure and arterial pressure monitoring was achieved using catheters in the right subclavian vein and femoral artery, installed under local anesthesia (LA). Epidural analgesia was achieved by using TEA, installed under LA, at T2/T3, $1 \mathrm{~h}$ before surgery; thoracic analgesia was achieved by bupivacaine $0.5 \%(+1.5 \mu \mathrm{g} / \mathrm{ml})$ at $2-$ $10 \mathrm{ml} / \mathrm{h}$. In addition, a femoral nerve block at the left leg was performed using $20 \mathrm{ml}$ of bupivacaine $0.5 \%$. Spontaneous respiration during surgery was aided using $100 \%$ oxygen applied via a face mask.

RESULTS. Ten male patients (mean age $63 \pm 10$ years, range 45 -83) with a mean ejection fraction $62 \% \pm 14 \%$ (range: $30-82 \%$ ) received $2.3 \pm 0.5$ (range: $2-3$ ) mammarian artery and saphenous vein grafts during $112 \pm 13 \mathrm{~min}$ (range: $90-140 \mathrm{~min}$ ). In one patient with an ejection fraction of $30 \%$, positioning of the heart for distal grafting lead to drop in blood pressure and conversion to on-pump grafting: here conversion to general anesthesia and intubation was achieved within $30 \mathrm{~s}$, grafting was performed on-pump and the patient extubated immediately after surgery without complications. In a second patient, TEA was insufficient for awake surgery; surgery was performed under combined general/regional anesthesia, the patient was equally extubated immediately after surgery without problems. In all other 8/10 patients, awake surgery was uneventful in stable hemodynamics (Figure 1). All ten patients were transferred to the PACU for $434 \pm 26$ min after which they were transferred to the cardiac ward (no intensive care stay).

DISCUSSION. Awake cardiac surgery using a combined TEA/FN allows OPCAB including saphenous vein grafts. In case of complication, the patient can be rapidly and safely intubated. Future studies need to define the place of awake cardiac surgery using this novel technique.

Figure 1 Representative hemodynamic variables and peripheral oxygen saturation, sternotomy starts at time $=0$.

1 Hemmerling at al. Can J Anaesth 2005 


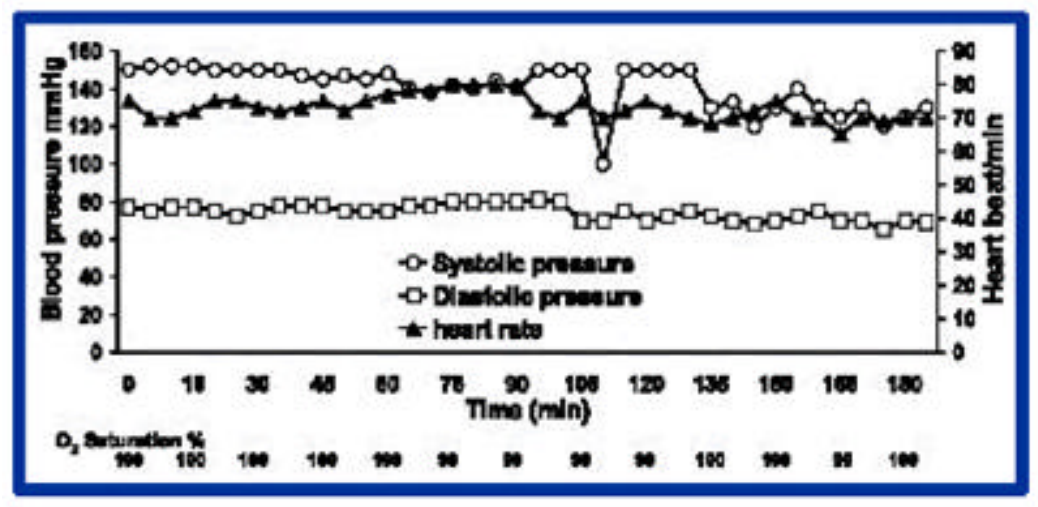

